\title{
Historiografia e Nação no Brasil - um clássico e suas possibilidades, da gênese da historiografia ao lugar da História Ensinada nos dias de hoje
} Historiografia e Nação no Brasil - a classic and its possibilities, from the beginnings of historiography until today

Mauro Cezar Coelho*

Guimarães, Manoel Luiz Salgado

Historiografia e Nação no Brasil (1838-1857)

Trad. Paulo Knauss e Ina de Mendonça

Rio de Janeiro: Ed. Uerj, 2011. 284p.

O livro de Manoel Luiz Salgado Guimarães, Historiografia e Nação no Brasil (1838-1857), ${ }^{1}$ me fez reviver, pelo que recordo, a primeira vez em que a História me chamou atenção: uma visita ao Museu Histórico Nacional, no começo da década de 1970. Lembro ter notado a convergência entre o que aprendia nos livros didáticos, nas revistas ilustradas, nas festas cívicas e na narrativa das professoras e o que via no Museu: uma história de grandes homens que superavam as limitações de seu tempo e o moldavam à sua vontade. O livro de Manoel Guimarães esclarece as origens da cultura histórica que engendrou a constatação feita por mim, naquela visita.

Ao desvendar as raízes da historiografia brasileira, Manoel Guimarães aponta os signos que a demarcaram desde o início. Essa, desde onde percebo, é uma contribuição importante e oportuna, no momento em que a formação do historiador passa por uma inflexão decisiva e o seu mais significante campo de atuação vive uma crise surda. A distinção dos cursos de bacharelado e licenciatura e os questionamentos sobre a importância da área de História na Educação Básica reeditam questões análogas àquelas presentes na origem da disciplina no Brasil.

\footnotetext{
* Faculdade de História, Programa de Pós-Graduação em História Social, Universidade Federal do Pará (UFPA). Av. Augusto Correa, 1, Guamá.66075.110 Belém - PA - Brasil. mauroccoelho@ yahoo.com.br
} 
O livro abarca os primeiros vinte anos de atuação do Instituto Histórico e Geográfico Brasileiro (IHGB). Nesse período, Manoel Guimarães identifica o "processo de promoção da nação brasileira", quando os estudos históricos buscaram atender aos objetivos de consolidação do Império e de formação da nação. Daí terem assumido importância política, a qual condicionou os seus primeiros passos e lhes delegou algumas de suas características mais duradouras.

A análise encaminha as conexões havidas entre os objetivos políticos e ideológicos do Império e a escrita produzida pelo IHGB. Identifico, nela, três movimentos. Primeiramente, as questões que importavam ao recém-constituído Império do Brasil: o contexto geopolítico no qual o país estava inserido; as relações entre as diversas regiões do Império; o perfil populacional, com imensas parcelas da população consideradas impróprias, diante do modelo de nação almejado. Em seguida, o perfil dos intelectuais ligados ao instituto. Em que pesem as diferenças de origem social, tinham em comum a formação - a Universidade de Coimbra - e a carreira - marcadamente dependente das oportunidades abertas pelo serviço público. Finalmente, a produção do IHGB. A questão indígena, o reconhecimento do território e os fatos históricos regionais ocuparam grande parte da produção da revista trimestral do instituto.

Os três movimentos sustentam um exame minucioso da cultura histórica que deu origem à historiografia brasileira. A análise que deles resulta desvenda os vínculos que ligavam o IHGB ao Estado imperial, tanto do ponto de vista programático (dos objetivos do instituto) quanto do ponto de vista operacional (a sua manutenção). Ela estabelece a identificação do instituto brasileiro com o modelo francês no qual se pautava. Ela esquadrinha a produção de seu sócio mais importante, Francisco Adolfo de Varnhagen, percebido como o formulador "da base da nacionalidade brasileira" a partir da perspectiva da elite imperial.

Trata-se de uma história da historiografia brasileira, demarcada pela indicação do significado assumido por ela, em meados do século XIX: para os sócios do instituto, a História constituía uma instância política - tanto de seu aprendizado, quando do seu exercício. Nesse sentido é que Manoel Guimarães encaminha a visão de história compartilhada pelos homens do instituto: uma história que se pretendia um manancial de exemplos e lições para os governos e comprometida com o progresso, desde certa perspectiva. Tal visão sustentou o caráter civilizador da escrita de uma História do Brasil, pelo IHGB, concre- 
tizado, sobretudo, pela consolidação de uma narrativa histórica que integrava os diversos elementos da população em acordo com uma ordenação que designasse o lugar de cada um, segundo uma hierarquia bem definida.

Da consideração da obra de Varnhagen, para quem a herança europeia deveria constituir a matriz da nacionalidade, emerge o argumento central do livro. A escrita da história do IHGB, demarcada pelos compromissos políticos com o Império, elegeu o Estado como principal agente, como "o motor da vida social", instituindo um ideal de nacionalidade profundamente dependente dos interesses da classe dirigente e por ela demarcado. Da mesma forma, ela pretendeu "gerar sentimentos condicionadores de uma comunidade como passo relevante para o surgimento da nação brasileira” (p.229-258). A história formulada a partir desses princípios acentuava a participação dos colonos brancos no passado e encaminhava a sua liderança no presente e no futuro. Ela orientava uma visão do passado que delegava para as margens imensas parcelas da população brasileira.

A reflexão presente em Historiografia e Nação no Brasil (1838-1857), desde a publicação de seu resumo, deu azo a diversos estudos sobre a trajetória da disciplina, conforme apontam Paulo Knauss e Temístocles Cézar. ${ }^{2}$ Essa, porém, não é sua única contribuição. Ela nos convida a refletir, também, sobre o quanto aquelas raízes permanecem latentes na cultura histórica, especialmente aquela difundida pelo saber histórico escolar. Esse, me parece, é um desafio importante que deriva da obra de Manoel Luiz Salgado Guimarães.

A remissão inicial à visita ao Museu Histórico Nacional e a relação que estabeleci, quando criança, entre o seu acervo e a narrativa que a disciplina História me apresentava não é fortuita. Ela ilustra a permanência daquele signo inicial que demarcou a historiografia brasileira e, sobretudo, a memória histórica. Manoel Guimarães deixa claro que a historiografia brasileira nasceu livre dos vínculos acadêmicos e em estreita relação com os imperativos políticos. Essa condição inicial foi decisiva para a produção subsequente, mesmo após a emergência de uma historiografia abalizada pelos ditames acadêmicos, determinando os rumos e usos da História entre nós. É certo que, desde a década de 1930, a historiografia problematiza tal herança, mas é igualmente certo que se a historiografia deixou de cumprir aquela função inicial e traçou outros rumos para si, o Ensino de História ainda se vê às voltas com ela. 
Ainda na década de 1970 e na seguinte, os historiadores que refletiam sobre o Ensino de História assumiram um novo compromisso: formar o cidadão - um objetivo relacionado aos ideais democráticos que lutavam para afirmar-se ao longo e ao final da Ditadura Militar. Desde então, 'formar o cidadão crítico' tem se constituído no apanágio do Ensino de História. A partir do que pontua a reflexão de Manoel Guimarães, poder-se-ia argumentar que a matriz inicial não foi superada, mas substituída. ${ }^{3}$ Não obstante, ela provoca a reflexão sobre o estatuto recentemente proposto e, principalmente, sobre a função e a importância do Ensino de História na Educação Básica, sua relação com a historiografia e seu lugar na constituição da memória histórica do Brasil de hoje.

Por mais de século e meio, os professores de História foram vistos (e se viram, também) como os responsáveis por transmitir a narrativa que inseria crianças e adolescentes no universo do qual faziam parte. Mesmo diante das críticas formuladas nas décadas de 1970 e 1980, essa responsabilidade permaneceu inalterada. Grande parte das aulas de história configura narrativas sobre o passado brasileiro e ocidental, ainda de uma perspectiva eurocêntrica - resultado, também, da matriz dos cursos de formação de professores. Dois fatores provocam a alteração desse quadro, desde fora, e colocam em questão a função da disciplina História em sala de aula: em primeiro lugar, a emergência de outros espaços a partir dos quais a memória histórica se constitui; em segundo lugar, a inclusão de novos agentes na narrativa sobre a formação do Brasil (refiro-me à inclusão da História da África, da Cultura Afro-brasileira e da História Indígena, na Educação Básica).

O livro de Manoel Luiz Salgado Guimarães sinaliza os caminhos a serem percorridos pelas reflexões que pretendam elucidar a trajetória da disciplina. Ele permite, portanto, entrever as questões que devem ser discutidas no que se refere à dimensão que incorpora e exige a atuação de um número imenso de historiadores: a Educação Básica. Desde onde falo, percebo três linhas de investigação necessariamente interligadas: a reflexão sobre a trajetória dos cursos de formação de professores em História - uma História da Formação; a reflexão sobre a prática docente em História - uma História do Ensino de História; e a reflexão sobre o estatuto do ensino de história na Educação Básica - uma História da Cultura Histórica Escolar.

Historiografia e Nação no Brasil (1838-1857) nasceu clássico. Ele não somente demarca uma periodização para a História da Historiografia, indicando 
o significado assumido por ela em dado momento, como inicia um campo de estudos. Isso já seria suficiente para torná-lo obra obrigatória. Mas, além de soberbamente escrito (o que acrescenta prazer à leitura), seu brilhantismo decorre das questões que suscita não apenas sobre o passado da disciplina, mas sobre seu presente e seu futuro. Ao desvendar as origens da historiografia brasileira, ele nos convida a pensar os percursos traçados por ela e seus desdobramentos. Neste momento, segundo me parece, esse convite deve ser aceito, de modo a refletir sobre seus rumos. Há que se discutir qual o lugar da História ensinada, qual a formação engendrada por ela, que compromissos lhe são pertinentes. Nosso agradecimento ao saudoso historiador pelo ensinamento e pela provocação. Boa leitura a todos!

\section{NOTAS}

${ }^{1}$ Originalmente uma tese de doutoramento defendida em 1987 na Universidade Livre de Berlim, sob a orientação do professor Hagen Schulze. Desde 1988, um resumo da tese orienta um sem-número de reflexões sobre o período: GUIMARÃES, Manoel Luiz Salgado. Nação e Civilização nos Trópicos: o Instituto Histórico e Geográfico Brasileiro e o projeto de uma História Nacional. Estudos Históricos, Rio de Janeiro: FGV, n.1, p.5-27, 1988.

${ }^{2}$ Ambos assinam o belíssimo ensaio que apresenta a obra: KNAUSS, Paulo; CEZAR, Temístocles. O historiador viajante: itinerário do Rio de Janeiro a Jerusalém (Prefácio). In: Historiografia e Nação no Brasil: 1838-1857. Rio de Janeiro: Ed. Uerj, 2011. p.7-21. Acrescento ao rol elaborado por eles as seguintes obras: D'INCAO, M. A. História e ideal: ensaios sobre Caio Prado Jr. São Paulo: Brasiliense; Ed. Unesp, 1989; SAMARA, Eni de Mesquita; SOIHET, Rachel; MATOS, Maria Izilda S. de. Gênero em debate: trajetórias e perspectivas na historiografia contemporânea. São Paulo: Educ, 1997; FREITAS, Marcos Cézar de (Org.) Historiografia brasileira em perspectiva. São Paulo: Contexto, 2001; SILVA, Rogério Forastieri da. História da historiografia: capítulos para uma história das histórias da historiografia. Bauru: Edusc, 2001; NEVES, Lúcia Maria Bastos Pereira; GUIMARÃES, Lúcia Maria Paschoal; GONÇALVES, Márcia de Almeida; GONTIJO, Rebeca. Estudos de historiografia brasileira. Rio de Janeiro: Ed. FGV, 2011.

${ }^{3}$ Sobre isso ver COELHO, Mauro Cezar. A história, o índio e o livro didático: apontamentos para uma reflexão sobre o saber histórico escolar. In: ROCHA, Helenice Aparecida Bastos; REZNIK, Luís; MAGALHÃES, Marcelo de Souza (Org.) A história na escola: autores, livros e leituras. Rio de Janeiro: Ed. FGV, 2009. p.263-280.

Resenha recebida em 10 de janeiro de 2012. Aprovada em 10 de março de 2012. 